\title{
COMMON FIXED POINT THEOREMS FOR A FAMILY OF MULTIVALUED F-CONTRACTIONS WITH AN APPLICATION TO SOLVE A SYSTEM OF INTEGRAL EQUATIONS
}

\author{
Tayyab Kamran, Fahimuddin and Muhammad Usman Ali \\ Quaid-i-Azam University and COMSATS Institute of Information \\ Technology, Pakistan
}

\begin{abstract}
Inspired by the work of Wardowski in [33] and Samet et al. in [26], in this article, we introduce some new contractive conditions for sequence of multi functions. We have constructed non-trivial examples to validate our results. We have applied our results to find a solution of a system of integral equations.
\end{abstract}

\section{INTRODUCTION}

The Banach contraction principle is a famous theorem in the field of fixed point theory and it is not wrong to say that it brought about a new era in metric fixed point theory. Since its inception, major and minor developments have been made regarding its generalization. In the recent past Wardowski ([33]) categorized some mappings into a new family and called it $F$ or $\mathfrak{F}$ family. Using the mappings from $\mathfrak{F}$ family he introduced a new contraction condition namely the $F$-contractions, which effectively generalized the famous Banach contraction condition. Several researchers studying metric fixed point theory have comprehensively generalized the Banach contraction condition, see for example $[2,30,25,18,13,29,22,24,28,20,1,26,6,21,7,19,14,3-5,15-17,27,12,31$, $11,9,10,8,23,32,33]$. Semat et al. in [26] also succeeded in generalizing Banach contraction condition by introducing $\alpha-\psi$-contraction. Many authors appreciated these two conditions which can be seen in $[6,21,7,19,14,3-5,15,16]$.

2010 Mathematics Subject Classification. 47H10, 54H25.

Key words and phrases. $\alpha$-admissible sequences, $\alpha_{*}$-admissible sequences, $F$ contractions. 
Keeping in view both of these ideas, in this paper we introduce new contraction conditions for a sequence of multifunction and prove corresponding fixed point theorem. We also give a common fixed point theorem for sequence of bounded multifunctions by using the $\delta$-distance. To conclude our findings we establish an existence theorem for a system of integral equations.

We gather some common results, notations and definitions, which are required for this paper. Let $(X, d)$ be a metric space. We denote the set of all nonempty subsets of $X$ by $N(X)$, the class of all nonempty closed subsets of $X$ by $C(X)$ and the class of all nonempty bounded subsets of $X$ by $B(X)$. For $b \in N(X), d(a, B)=\inf \{d(a, b): b \in N(X)\}$. For $A, B \in B(X)$, $\delta(A, B)=\sup \{d(a, b): a \in A, b \in B\}$. Note that $\delta$ satisfies all conditions of a metric, except $A=B \Rightarrow \delta(A, B)=0$. For $A, B \in C(X)$, the generalized Hausdorff metric on $C(X)$ is given as,

$H(A, B)=\left\{\begin{array}{l}\max \left\{\sup _{x \in A} d(x, B), \sup _{y \in B} d(y, A)\right\} \text { if the maximum exists } \\ \infty \text { otherwise }\end{array}\right.$

Wardowski [33] introduced the following definition.

Definition 1.1. Let $\mathfrak{F}$ be the class of all functions $F:(0, \infty) \rightarrow \mathbb{R}$ satisfying:

$\left(F_{1}\right) F$ is increasing, that is, for each $a_{1}, a_{2} \in(0, \infty)$ with $a_{1}<a_{2}$, we have $F\left(a_{1}\right)<F\left(a_{2}\right)$.

$\left(F_{2}\right)$ For each sequence $\left\{\mathfrak{d}_{n}\right\}$ of positive real numbers we have $\lim _{n \rightarrow \infty} \mathfrak{d}_{n}=$ 0 if and only if $\lim _{n \rightarrow \infty} F\left(\mathfrak{d}_{n}\right)=-\infty$.

$\left(F_{3}\right)$ There exists $k \in(0,1)$ such that $\lim _{\mathfrak{d} \rightarrow 0^{+}} \mathfrak{d}^{k} F(\mathfrak{d})=0$.

Following are some examples of such functions.

(i) $F_{a}=\ln a$ for each $a \in(0, \infty)$.

(ii) $F_{b}=b+\ln b$ for each $b \in(0, \infty)$.

(iii) $F_{c}=-\frac{1}{\sqrt{c}}$ for each $c \in(0, \infty)$.

Wardowski ([33]) introduced $F$-contraction and proved corresponding fixed point theorem as,

Definition $1.2([33])$. Let $(X, d)$ be a metric space. A mapping $T: X \rightarrow$ $X$ is $F$-contraction if there exist $F \in \mathfrak{F}$ and $\tau>0$ such that for each $x, y \in X$ with $d(T x, T y)>0$, we have

$$
\tau+F(d(T x, T y)) \leq F(d(x, y)) .
$$

Note that if $T$ is $F_{a}$-contraction, then it is also Banach contraction. This it is not in the case for $F_{b}$-contraction.

TheOREM $1.3([33])$. Let $(X, d)$ be a complete metric space and let $T$ : $X \rightarrow X$ be $F$-contraction. Then $T$ has a unique fixed point.

Sgroi and Vetro [29] introduced the following theorem. 
TheOrem $1.4([29])$. Let $(X, d)$ be a complete metric space and let $T$ : $X \rightarrow C B(X)$. Assume that there exist $F \in \mathfrak{F}$ and $\tau>0$ such that

$$
\begin{aligned}
2 \tau+F(H(T x, T y)) \leq & F\left(a_{1} d(x, y)+a_{2} d(x, T x)+a_{3} d(y, T y)\right. \\
& \left.+a_{4} d(x, T y)+L d(y, T x)\right),
\end{aligned}
$$

for each $x, y \in X$ with $T x \neq T y$, where $a_{1}, a_{2}, a_{3}, a_{4}, L \geq 0$ satisfying $a_{1}+$ $a_{2}+a_{3}+2 a_{4}=1$ and $a_{3} \neq 1$. Then $T$ has a fixed point.

\section{MAIN RESUlts}

We begin this section by introducing the following definitions.

Definition 2.1. Let $\alpha: X \times X \rightarrow[0, \infty)$. A sequence of mappings $\left\{T_{i}: X \rightarrow N(X)\right\}_{i=1}^{\infty}$ is $\alpha$-admissible sequence if for each $x \in X$ and $y \in T_{i} x$ for some $i \in \mathbb{N}$ such that $\alpha(x, y) \geq 1$, then we have $\alpha(y, z) \geq 1$ for each $z \in T_{i+1} y$. A sequence of mappings $\left\{T_{i}: X \rightarrow N(X)\right\}_{i=1}^{\infty}$ is $\alpha_{*}$-admissible sequence if for each $x, y \in X$ with $\alpha(x, y) \geq 1$, we have $\alpha_{*}\left(T_{i} x, T_{j} y\right) \geq 1$ for each $i, j \in \mathbb{N}$, where $\alpha_{*}\left(T_{i} x, T_{j} y\right)=\inf \left\{\alpha(u, v): u \in T_{i} x\right.$ and $\left.v \in T_{j} y\right\}$.

The sequence of mappings is said to be strictly $\alpha$-admissible and strictly $\alpha_{*}$-admissible if we have strict inequality in the above definition.

REMARK 2.2. (i) Note that if a sequence of mappings $\left\{T_{i}: X \rightarrow\right.$ $N(X)\}_{i=1}^{\infty}$ is strictly $\alpha_{*}$-admissible sequence, then it is strictly $\alpha$ admissible sequence.

(ii) When $\left\{T_{i}\right\}_{i=1}^{\infty}$ is a constant sequence Definition 2.1 coincide with definition of $\alpha$-admissible and $\alpha_{*}$-admissible given in [21, Page 4] and [7, Page 1] respectively. Furthermore, if $T$ is a singlevalued mapping then these definition 2.1 coincide with [26, Definition 2.2].

Definition 2.3. Let $(X, d)$ be a metric space and $\alpha: X \times X \rightarrow[0, \infty)$ be a function. A sequence of mappings $\left\{T_{i}: X \rightarrow C(X)\right\}_{i=1}^{\infty}$ is an $F_{\alpha}$-contraction of Hardy-Rogers-type, if there exist $F \in \mathfrak{F}$ and $\tau>0$ such that for each $i, j \in \mathbb{N}$, we have

$$
\tau+F\left(\alpha(x, y) H\left(T_{i} x, T_{j} y\right)\right) \leq F(N(x, y)),
$$

for each $x, y \in X$, whenever $\min \left\{\alpha(x, y) H\left(T_{i} x, T_{j} y\right), N(x, y)\right\}>0$, where

$N(x, y)=a_{1} d(x, y)+a_{2} d\left(x, T_{i} x\right)+a_{3} d\left(y, T_{j} y\right)+a_{4} d\left(x, T_{j} y\right)+L d\left(y, T_{i} x\right)$, with $a_{1}, a_{2}, a_{3}, a_{4}, L \geq 0$ satisfying $a_{1}+a_{2}+a_{3}+2 a_{4}=1$ and $a_{3} \neq 1$.

TheOREm 2.4. Let $(X, d)$ be a complete metric space and let $\left\{T_{i}: X \rightarrow\right.$ $C(X)\}_{i=1}^{\infty}$ be an $F_{\alpha}$-contraction of Hardy-Rogers-type satisfying the following conditions:

(i) $\left\{T_{i}\right\}_{i=1}^{\infty}$ is strictly $\alpha$-admissible sequence;

(ii) there exist $x_{0} \in X$ and $x_{1} \in T_{i} x_{0}$ for some $i \in \mathbb{N}$ with $\alpha\left(x_{0}, x_{1}\right)>1$; 
(iii) for any sequence $\left\{x_{n}\right\} \subseteq X$ such that $x_{n} \rightarrow x$ as $n \rightarrow \infty$ and $\alpha\left(x_{n}, x_{n+1}\right)>1$ for each $n \in \mathbb{N}$, we have $\alpha\left(x_{n}, x\right)>1$ for each $n \in \mathbb{N}$.

Then the mappings in the sequence $\left\{T_{i}\right\}_{i=1}^{\infty}$ have a common fixed point.

Proof. By hypothesis (ii), we assume without loss of generality that there exist $x_{0} \in X$ and $x_{1} \in T_{1} x_{0}$ with $\alpha\left(x_{0}, x_{1}\right)>1$. If $x_{1} \in T_{i} x_{1} \forall i \in \mathbb{N}$, then $x_{1}$ is a common fixed point. Let $x_{1} \notin T_{2} x_{1}$, as $\alpha\left(x_{0}, x_{1}\right)>1$ there exists $x_{2} \in T_{2} x_{1}$ such that

$$
d\left(x_{1}, x_{2}\right) \leq \alpha\left(x_{0}, x_{1}\right) H\left(T_{1} x_{0}, T_{2} x_{1}\right) .
$$

Since $F$ is increasing, we have

$$
F\left(d\left(x_{1}, x_{2}\right)\right) \leq F\left(\alpha\left(x_{0}, x_{1}\right) H\left(T_{1} x_{0}, T_{2} x_{1}\right)\right) .
$$

From (2.1) we have

$$
\begin{aligned}
\tau+F\left(d\left(x_{1}, x_{2}\right)\right) \leq & \tau+F\left(\alpha\left(x_{0}, x_{1}\right) H\left(T_{1} x_{0}, T_{2} x_{1}\right)\right) \\
\leq & F\left(a_{1} d\left(x_{0}, x_{1}\right)+a_{2} d\left(x_{0}, T_{1} x_{0}\right)+a_{3} d\left(x_{1}, T_{2} x_{1}\right)\right. \\
& \left.+a_{4} d\left(x_{0}, T_{2} x_{1}\right)+L d\left(x_{1}, T_{1} x_{0}\right)\right) \\
\leq & F\left(a_{1} d\left(x_{0}, x_{1}\right)+a_{2} d\left(x_{0}, x_{1}\right)+a_{3} d\left(x_{1}, x_{2}\right)\right. \\
& \left.+a_{4} d\left(x_{0}, x_{2}\right)+L .0\right) \\
\leq & F\left(a_{1} d\left(x_{0}, x_{1}\right)+a_{2} d\left(x_{0}, x_{1}\right)+a_{3} d\left(x_{1}, x_{2}\right)\right. \\
& +a_{4}\left(d\left(x_{0}, x_{1}\right)+d\left(x_{1}, x_{2}\right)\right) \\
= & F\left(\left(a_{1}+a_{2}+a_{4}\right) d\left(x_{0}, x_{1}\right)+\left(a_{3}+a_{4}\right) d\left(x_{1}, x_{2}\right)\right) .
\end{aligned}
$$

Since $F$ is increasing, we get from above that

$$
d\left(x_{1}, x_{2}\right)<\left(a_{1}+a_{2}+a_{4}\right) d\left(x_{0}, x_{1}\right)+\left(a_{3}+a_{4}\right) d\left(x_{1}, x_{2}\right) .
$$

That is,

$$
\left(1-a_{3}-a_{4}\right) d\left(x_{1}, x_{2}\right)<\left(a_{1}+a_{2}+a_{4}\right) d\left(x_{0}, x_{1}\right) .
$$

As $a_{1}+a_{2}+a_{3}+2 a_{4}=1$, thus we have

$$
d\left(x_{1}, x_{2}\right)<d\left(x_{0}, x_{1}\right) .
$$

From (2.4), we have

$$
\tau+F\left(d\left(x_{1}, x_{2}\right)\right) \leq F\left(d\left(x_{0}, x_{1}\right)\right) .
$$

If $x_{2} \in T_{i} x_{2} \forall i \in \mathbb{N}$ then $x_{2}$ is a common fixed point. Let $x_{2} \notin T_{3} x_{2}$. Since $\left\{T_{i}\right\}_{i=1}^{\infty}$ is strictly $\alpha$-admissible, we have $\alpha\left(x_{1}, x_{2}\right)>1$. There exists $x_{3} \in T_{3} x_{2}$ such that

$$
d\left(x_{2}, x_{3}\right) \leq \alpha\left(x_{1}, x_{2}\right) H\left(T_{2} x_{1}, T_{3} x_{2}\right)
$$

Since $F$ is increasing, we have

$$
F\left(d\left(x_{2}, x_{3}\right)\right) \leq F\left(\alpha\left(x_{1}, x_{2}\right) H\left(T_{2} x_{1}, T_{3} x_{2}\right)\right) .
$$


From (2.1) we have

$$
\begin{aligned}
\tau+F\left(d\left(x_{2}, x_{3}\right)\right) \leq & \tau+F\left(\alpha\left(x_{1}, x_{2}\right) H\left(T_{2} x_{1}, T_{3} x_{2}\right)\right) \\
\leq & F\left(a_{1} d\left(x_{1}, x_{2}\right)+a_{2} d\left(x_{1}, T_{2} x_{1}\right)+a_{3} d\left(x_{2}, T_{3} x_{2}\right)\right. \\
& \left.+a_{4} d\left(x_{1}, T_{3} x_{2}\right)+L d\left(x_{2}, T_{2} x_{1}\right)\right) \\
\leq & F\left(a_{1} d\left(x_{1}, x_{2}\right)+a_{2} d\left(x_{1}, x_{2}\right)+a_{3} d\left(x_{2}, x_{3}\right)\right. \\
& \left.+a_{4} d\left(x_{1}, x_{3}\right)+L .0\right) \\
\leq & F\left(a_{1} d\left(x_{1}, x_{2}\right)+a_{2} d\left(x_{1}, x_{2}\right)+a_{3} d\left(x_{2}, x_{3}\right)\right. \\
& +a_{4}\left(d\left(x_{1}, x_{2}\right)+d\left(x_{2}, x_{3}\right)\right) \\
= & F\left(\left(a_{1}+a_{2}+a_{4}\right) d\left(x_{1}, x_{2}\right)+\left(a_{3}+a_{4}\right) d\left(x_{2}, x_{3}\right)\right) .
\end{aligned}
$$

Since $F$ is increasing, we get from above that

$$
d\left(x_{2}, x_{3}\right)<\left(a_{1}+a_{2}+a_{4}\right) d\left(x_{1}, x_{2}\right)+\left(a_{3}+a_{4}\right) d\left(x_{2}, x_{3}\right) .
$$

That is,

$$
\left(1-a_{3}-a_{4}\right) d\left(x_{2}, x_{3}\right)<\left(a_{1}+a_{2}+a_{4}\right) d\left(x_{1}, x_{2}\right) .
$$

As $a_{1}+a_{2}+a_{3}+2 a_{4}=1$, thus we have

$$
d\left(x_{2}, x_{3}\right)<d\left(x_{1}, x_{2}\right) .
$$

Now from (2.7) we have

$$
\tau+F\left(d\left(x_{2}, x_{3}\right)\right) \leq F\left(d\left(x_{1}, x_{2}\right)\right) .
$$

So we have

$$
F\left(d\left(x_{2}, x_{3}\right)\right) \leq F\left(d\left(x_{1}, x_{2}\right)\right)-\tau \leq F\left(d\left(x_{0}, x_{1}\right)\right)-2 \tau .
$$

Continuing in the same way we get a sequence $\left\{x_{n}\right\} \subset X$ such that

$$
x_{n} \in T_{n} x_{n-1}, x_{n-1} \neq x_{n} \text { and } \alpha\left(x_{n-1}, x_{n}\right)>1 \text { for each } n \in \mathbb{N} \text {. }
$$

Furthermore,

$$
F\left(d\left(x_{n}, x_{n+1}\right)\right) \leq F\left(d\left(x_{0}, x_{1}\right)\right)-n \tau \text { for each } n \in \mathbb{N} .
$$

Letting $n \rightarrow \infty$ in $(2.8)$ we get $\lim _{n \rightarrow \infty} F\left(d\left(x_{n}, x_{n+1}\right)\right)=-\infty$. Thus by property $\left(F_{2}\right)$, we have $\lim _{n \rightarrow \infty} d\left(x_{n}, x_{n+1}\right)=0$. Let $d_{n}=d\left(x_{n}, x_{n+1}\right)$ for each $n \in \mathbb{N}$. From $\left(F_{3}\right)$ there exists $k \in(0,1)$ such that

$$
\lim _{n \rightarrow \infty} d_{n}^{k} F\left(d_{n}\right)=0 \text {. }
$$

From (2.8) we have

$$
d_{n}^{k} F\left(d_{n}\right)-d_{n}^{k} F\left(d_{0}\right) \leq-d_{n}^{k} n \tau \leq 0 \text { for each } n \in \mathbb{N} .
$$

Letting $n \rightarrow \infty$ in (2.9) we get,

$$
\lim _{n \rightarrow \infty} n d_{n}^{k}=0 .
$$


This implies that there exists $n_{1} \in \mathbb{N}$ such that $n d_{n}^{k} \leq 1$ for each $n \geq n_{1}$. Thus we have

$$
d_{n} \leq \frac{1}{n^{1 / k}}, \text { for each } n \geq n_{1} .
$$

To prove that $\left\{x_{n}\right\}$ is a Cauchy sequence. Consider $m, n \in \mathbb{N}$ with $m>n>$ $n_{1}$. By using the triangular inequality and (2.11), we have

$$
\begin{aligned}
d\left(x_{n}, x_{m}\right) & \leq d\left(x_{n}, x_{n+1}\right)+d\left(x_{n+1}, x_{n+2}\right)+\cdots+d\left(x_{m-1}, x_{m}\right) \\
& =\sum_{i=n}^{m-1} d_{i} \leq \sum_{i=n}^{\infty} d_{i} \leq \sum_{i=n}^{\infty} \frac{1}{i^{1 / k}} .
\end{aligned}
$$

Since $\sum_{i=1}^{\infty} \frac{1}{i^{1 / k}}$ is convergent series. Thus, $\lim _{n \rightarrow \infty} d\left(x_{n}, x_{m}\right)=0$. Which implies that $\left\{x_{n}\right\}$ is a Cauchy sequence. As $(X, d)$ is complete, there exists $x^{*} \in X$ such that $x_{n} \rightarrow x^{*}$ as $n \rightarrow \infty$. By condition (iii) we have $\alpha\left(x_{n}, x^{*}\right)>$ 1 for each $n \in \mathbb{N}$. We claim that $d\left(x^{*}, T_{i} x^{*}\right)=0 \forall i \in \mathbb{N}$. On contrary suppose that $d\left(x^{*}, T_{i_{0}} x^{*}\right)>0$ for some $i_{0} \in \mathbb{N}$, there exists $n_{0} \in \mathbb{N}$ such that $d\left(x_{n}, T_{i_{0}} x^{*}\right)>0$ for each $n \geq n_{0}$. For each $n \geq n_{0}$ and for above $i_{0}$ we have

$$
\begin{aligned}
d\left(x^{*}, T_{i_{0}} x^{*}\right) \leq & d\left(x^{*}, x_{n+1}\right)+d\left(x_{n+1}, T_{i_{0}} x^{*}\right) \\
< & d\left(x^{*}, x_{n+1}\right)+\alpha\left(x_{n}, x^{*}\right) H\left(T_{n+1} x_{n}, T_{i_{0}} x^{*}\right) \\
< & d\left(x^{*}, x_{n+1}\right)+a_{1} d\left(x_{n}, x^{*}\right)+a_{2} d\left(x_{n}, x_{n+1}\right) \\
& +a_{3} d\left(x^{*}, T_{i_{0}} x^{*}\right)+a_{4} d\left(x_{n}, T_{i} x^{*}\right)+L d\left(x^{*}, x_{n+1}\right) .
\end{aligned}
$$

Letting $n \rightarrow \infty$ in (2.12) we have

$$
d\left(x^{*}, T_{i_{0}} x^{*}\right) \leq\left(a_{3}+a_{4}\right) d\left(x^{*}, T_{i_{0}} x^{*}\right)<d\left(x^{*}, T_{i_{0}} x^{*}\right) .
$$

Which is a contradiction. Thus $d\left(x^{*}, T_{i} x^{*}\right)=0 \forall i \in \mathbb{N}$.

ExAmple 2.5. Let $X=\mathbb{N}$ be endowed with the usual metric $d(x, y)=$ $|x-y|$ for each $x, y \in X$. Define $\left\{T_{i}: X \rightarrow C(X)\right\}_{i=1}^{\infty}$ by

$$
T_{i} x=\left\{\begin{array}{l}
\{0,1\} \text { if } x=0,1, \\
\{2 x-2,2 x\} \text { if } x>1
\end{array}\right.
$$

and $\alpha: X \times X \rightarrow[0, \infty)$ by

$$
\alpha(x, y)=\left\{\begin{array}{l}
2 \text { if } x, y \in\{0,1\} \\
\frac{1}{4} \text { if } x, y>1 \\
0 \text { otherwise }
\end{array}\right.
$$

Take $F(x)=x+\ln x$ for each $x \in(0, \infty)$. Under this $F$ condition $(2.1)$ reduces to

$$
\frac{\alpha(x, y) H\left(T_{i} x, T_{j} y\right)}{N(x, y)} e^{\alpha(x, y) H\left(T_{i} x, T_{j} y\right)-N(x, y)} \leq e^{-\tau}
$$


for each $x, y \in X$ with $\min \left\{\alpha(x, y) H\left(T_{i} x, T_{j} y\right), N(x, y)\right\}>0$. Assume that $a_{1}=1, a_{2}=a_{3}=a_{4}=L=0$ and $\tau=\frac{1}{2}$. Clearly,

$$
\min \left\{\alpha(x, y) H\left(T_{i} x, T_{j} y\right), d(x, y)\right\}>0
$$

for each $x, y>1$ with $x \neq y$. From (2.13) for each $x, y>1$ with $x \neq y$ we have

$$
\frac{1}{4} e^{-\frac{1}{2}|x-y|}<e^{-\frac{1}{2}} .
$$

Thus $\left\{T_{i}\right\}_{i=1}^{\infty}$ is an $\alpha$-F-contraction of Hardy-Rogers-type with $F(x)=x+$ $\ln x$. For $x_{0}=1$ we have $x_{1}=0 \in T_{1} x_{0}$ such that $\alpha\left(x_{0}, x_{1}\right)>1$. Moreover, it is easy to see that $\left\{T_{i}\right\}_{i=1}^{\infty}$ is strictly $\alpha$-admissible sequence and for any sequence $\left\{x_{n}\right\} \subseteq X$ such that $x_{n} \rightarrow x$ as $n \rightarrow \infty$ and $\alpha\left(x_{n}, x_{n+1}\right)>1$ for each $n \in \mathbb{N}$, we have $\alpha\left(x_{n}, x\right)>1$ for each $n \in \mathbb{N}$. Therefore, by Theorem 2.4 $\left\{T_{i}\right\}_{i=1}^{\infty}$ has a common fixed point in $X$.

Definition 2.6. Let $(X, d)$ be a metric space and $\alpha: X \times X \rightarrow[0, \infty)$ be a function. A sequence of mappings $\left\{T_{i}: X \rightarrow C(X)\right\}_{i=1}^{\infty}$ is an $F_{\alpha}$ *contraction of Hardy-Rogers-type, if there exist $F \in \mathfrak{F}$ and $\tau>0$ such that for each $i, j \in \mathbb{N}$, we have

$$
\tau+F\left(\alpha_{*}\left(T_{i} x, T_{j} y\right) H\left(T_{i} x, T_{j} y\right)\right) \leq F(N(x, y)),
$$

for each $x, y \in X$, whenever

$$
\min \left\{\alpha_{*}\left(T_{i} x, T_{j} y\right) H\left(T_{i} x, T_{j} y\right), N(x, y)\right\}>0,
$$

where

$$
N(x, y)=a_{1} d(x, y)+a_{2} d\left(x, T_{i} x\right)+a_{3} d\left(y, T_{j} y\right)+a_{4} d\left(x, T_{j} y\right)+L d\left(y, T_{i} x\right),
$$

with $a_{1}, a_{2}, a_{3}, a_{4}, L \geq 0$ satisfying $a_{1}+a_{2}+a_{3}+2 a_{4}=1$ and $a_{3} \neq 1$.

Theorem 2.7. Let $(X, d)$ be a complete metric space and let $\left\{T_{i}: X \rightarrow\right.$ $C(X)\}_{i=1}^{\infty}$ be an $\alpha_{*}-F$-contraction of Hardy-Rogers-type satisfying the following conditions:

(i) $\left\{T_{i}\right\}_{i=1}^{\infty}$ is strictly $\alpha_{*}$-admissible sequence;

(ii) there exist $x_{0} \in X$ and $x_{1} \in T_{i} x_{0}$ for some $i \in \mathbb{N}$ with $\alpha\left(x_{0}, x_{1}\right)>1$;

(iii) for any sequence $\left\{x_{n}\right\} \subseteq X$ such that $x_{n} \rightarrow x$ as $n \rightarrow \infty$ and $\alpha\left(x_{n}, x_{n+1}\right)>1$ for each $n \in \mathbb{N}$, we have $\alpha\left(x_{n}, x\right)>1$ for each $n \in \mathbb{N}$. Then the mappings in a sequence $\left\{T_{i}\right\}_{i=1}^{n}$ have a common fixed point.

Proof. The proof of this theorem runs along the same lines as the proof of Theorem 2.9.

Definition 2.8. Let $(X, d)$ be a metric space and $\alpha: X \times X \rightarrow[0, \infty)$ be a function. A sequence of mappings $\left\{T_{i}: X \rightarrow B(X)\right\}_{i=1}^{\infty}$ is an $F_{\alpha}$-contraction of Hardy-Rogers-type, if there exist $F \in \mathfrak{F}$ and $\tau>0$ such that for each $i, j \in \mathbb{N}$, we have

$$
\tau+F\left(\alpha(x, y) \delta\left(T_{i} x, T_{j} y\right)\right) \leq F(N(x, y)),
$$


for each $x, y \in X$, whenever $\min \left\{\alpha(x, y) \delta\left(T_{i} x, T_{j} y\right), N(x, y)\right\}>0$, where

$$
\begin{aligned}
N(x, y)= & a_{1} d(x, y)+a_{2} d\left(x, T_{i} x\right)+a_{3} d\left(y, T_{j} y\right) \\
& +a_{4} d\left(x, T_{j} y\right)+L d\left(y, T_{i} x\right),
\end{aligned}
$$

with $a_{1}, a_{2}, a_{3}, a_{4}, L \geq 0$ satisfying $a_{1}+a_{2}+a_{3}+2 a_{4}=1$ and $a_{3} \neq 1$.

Note that $H$ is not a metric on the set of bounded subsets of $X$, as the following example shows.

Let $X=\mathbb{R}$, endowed with usual metric then $H(A, B)=0$ but $A \neq B$ for $A=[0,1)$ and $B=[0,1]$. This implies that $H$ is not a metric on Bounded subsets of $\mathbb{R}$. It would be interesting to see whether the conclusions of Theorem 2.4 hold for bounded subsets of $X$. We will show that the conclusions of Theorem 2.4 still hold for bounded subsets of $X$ provided that the Housdorff distance $H(A, B)$ in definition 2.3 is replaced with $\delta(A, B)$ and the strict inequality in (ii) of Theorem 2.4 is replaced by the soft inequality. More precisely we have the following result.

Theorem 2.9. Let $(X, d)$ be a complete metric space and let $\left\{T_{i}: X \rightarrow\right.$ $B(X)\}_{i=1}^{\infty}$ be an $F_{\alpha}$-contraction of Hardy-Rogers-type satisfying the following conditions:

(i) $\left\{T_{i}\right\}_{i=1}^{\infty}$ is $\alpha$-admissible sequence;

(ii) there exist $x_{0} \in X$ and $x_{1} \in T_{i} x_{0}$ for some $i \in \mathbb{N}$ with $\alpha\left(x_{0}, x_{1}\right) \geq 1$;

(iii) for any sequence $\left\{x_{n}\right\} \subseteq X$ such that $x_{n} \rightarrow x$ as $n \rightarrow \infty$ and $\alpha\left(x_{n}, x_{n+1}\right) \geq 1$ for each $n \in \mathbb{N}$, we have $\alpha\left(x_{n}, x\right) \geq 1$ for each $n \in \mathbb{N}$.

Then the mappings in the sequence $\left\{T_{i}\right\}_{i=1}^{\infty}$ have a common fixed point.

Proof. By hypothesis (ii), we assume without loss of generality that there exist $x_{0} \in X$ and $x_{1} \in T_{1} x_{0}$ with $\alpha\left(x_{0}, x_{1}\right) \geq 1$. If $x_{1} \in T_{i} x_{1} \forall i \in \mathbb{N}$, then $x_{1}$ is a common fixed point. Let $x_{1} \notin T_{2} x_{1}$. As $\alpha\left(x_{0}, x_{1}\right) \geq 1$, there exists $x_{2} \in T_{2} x_{1}$ such that

$$
d\left(x_{1}, x_{2}\right) \leq \alpha\left(x_{0}, x_{1}\right) \delta\left(T_{1} x_{0}, T_{2} x_{1}\right)
$$

Since $F$ is increasing, we have

$$
F\left(d\left(x_{1}, x_{2}\right)\right) \leq F\left(\alpha\left(x_{0}, x_{1}\right) \delta\left(T_{1} x_{0}, T_{2} x_{1}\right)\right)
$$


From (2.15) we have

$$
\begin{aligned}
\tau+F\left(d\left(x_{1}, x_{2}\right)\right) \leq & \tau+F\left(\alpha\left(x_{0}, x_{1}\right) \delta\left(T_{1} x_{0}, T_{2} x_{1}\right)\right) \\
\leq & F\left(a_{1} d\left(x_{0}, x_{1}\right)+a_{2} d\left(x_{0}, T_{1} x_{0}\right)+a_{3} d\left(x_{1}, T_{2} x_{1}\right)\right. \\
& \left.+a_{4} d\left(x_{0}, T_{2} x_{1}\right)+L d\left(x_{1}, T_{1} x_{0}\right)\right) \\
\leq & F\left(a_{1} d\left(x_{0}, x_{1}\right)+a_{2} d\left(x_{0}, x_{1}\right)+a_{3} d\left(x_{1}, x_{2}\right)\right. \\
& \left.+a_{4} d\left(x_{0}, x_{2}\right)+L .0\right) \\
\leq & F\left(a_{1} d\left(x_{0}, x_{1}\right)+a_{2} d\left(x_{0}, x_{1}\right)+a_{3} d\left(x_{1}, x_{2}\right)\right. \\
& +a_{4}\left(d\left(x_{0}, x_{1}\right)+d\left(x_{1}, x_{2}\right)\right) \\
= & F\left(\left(a_{1}+a_{2}+a_{4}\right) d\left(x_{0}, x_{1}\right)+\left(a_{3}+a_{4}\right) d\left(x_{1}, x_{2}\right)\right) .
\end{aligned}
$$

Since $F$ is increasing, we get from above that

$$
d\left(x_{1}, x_{2}\right)<\left(a_{1}+a_{2}+a_{4}\right) d\left(x_{0}, x_{1}\right)+\left(a_{3}+a_{4}\right) d\left(x_{1}, x_{2}\right) .
$$

That is,

$$
\left(1-a_{3}-a_{4}\right) d\left(x_{1}, x_{2}\right)<\left(a_{1}+a_{2}+a_{4}\right) d\left(x_{0}, x_{1}\right) .
$$

As $a_{1}+a_{2}+a_{3}+2 a_{4}=1$, thus we have

$$
d\left(x_{1}, x_{2}\right)<d\left(x_{0}, x_{1}\right) .
$$

Now from (2.18), we have

$$
\tau+F\left(d\left(x_{1}, x_{2}\right)\right) \leq F\left(d\left(x_{0}, x_{1}\right)\right) .
$$

If $x_{2} \in T_{i} x_{2} \forall i \in \mathbb{N}$ then $x_{2}$ is a common fixed point. Let $x_{2} \notin T_{3} x_{2}$, since $\left\{T_{i}\right\}_{i=1}^{\infty}$ is $\alpha$-admissible, we have $\alpha\left(x_{1}, x_{2}\right) \geq 1$. There exists $x_{3} \in T_{3} x_{2}$ such that

$$
d\left(x_{2}, x_{3}\right) \leq \alpha\left(x_{1}, x_{2}\right) \delta\left(T_{2} x_{1}, T_{3} x_{2}\right) .
$$

Since $F$ is increasing, we have

$$
F\left(d\left(x_{2}, x_{3}\right)\right) \leq F\left(\alpha\left(x_{1}, x_{2}\right) \delta\left(T_{2} x_{1}, T_{3} x_{2}\right)\right) .
$$

From (2.15) we have

$$
\begin{aligned}
\tau+F\left(d\left(x_{2}, x_{3}\right)\right) \leq & \tau+F\left(\alpha\left(x_{1}, x_{2}\right) \delta\left(T_{2} x_{1}, T_{3} x_{2}\right)\right) \\
\leq & F\left(a_{1} d\left(x_{1}, x_{2}\right)+a_{2} d\left(x_{1}, T_{2} x_{1}\right)+a_{3} d\left(x_{2}, T_{3} x_{2}\right)\right. \\
& \left.+a_{4} d\left(x_{1}, T_{3} x_{2}\right)+L d\left(x_{2}, T_{2} x_{1}\right)\right) \\
\leq & F\left(a_{1} d\left(x_{1}, x_{2}\right)+a_{2} d\left(x_{1}, x_{2}\right)+a_{3} d\left(x_{2}, x_{3}\right)\right. \\
& \left.+a_{4} d\left(x_{1}, x_{3}\right)+L .0\right) \\
\leq & F\left(a_{1} d\left(x_{1}, x_{2}\right)+a_{2} d\left(x_{1}, x_{2}\right)+a_{3} d\left(x_{2}, x_{3}\right)\right. \\
& +a_{4}\left(d\left(x_{1}, x_{2}\right)+d\left(x_{2}, x_{3}\right)\right) \\
= & F\left(\left(a_{1}+a_{2}+a_{4}\right) d\left(x_{1}, x_{2}\right)+\left(a_{3}+a_{4}\right) d\left(x_{2}, x_{3}\right)\right) .
\end{aligned}
$$


Since $F$ is increasing, we get from above that

$$
d\left(x_{2}, x_{3}\right)<\left(a_{1}+a_{2}+a_{4}\right) d\left(x_{1}, x_{2}\right)+\left(a_{3}+a_{4}\right) d\left(x_{2}, x_{3}\right) .
$$

That is,

$$
\left(1-a_{3}-a_{4}\right) d\left(x_{2}, x_{3}\right)<\left(a_{1}+a_{2}+a_{4}\right) d\left(x_{1}, x_{2}\right) .
$$

As $a_{1}+a_{2}+a_{3}+2 a_{4}=1$, thus we have

$$
d\left(x_{2}, x_{3}\right)<d\left(x_{1}, x_{2}\right) .
$$

Now from (2.21) we have

$$
\tau+F\left(d\left(x_{2}, x_{3}\right)\right) \leq F\left(d\left(x_{1}, x_{2}\right)\right) .
$$

So we have

$$
F\left(d\left(x_{2}, x_{3}\right)\right) \leq F\left(d\left(x_{1}, x_{2}\right)\right)-\tau \leq F\left(d\left(x_{0}, x_{1}\right)\right)-2 \tau .
$$

Continuing in the same way we get a sequence $\left\{x_{n}\right\} \subset X$ such that

$$
x_{n} \in T_{n} x_{n-1}, x_{n-1} \neq x_{n} \text { and } \alpha\left(x_{n-1}, x_{n}\right) \geq 1 \text { for each } n \in \mathbb{N} .
$$

Furthermore,

$$
F\left(d\left(x_{n}, x_{n+1}\right)\right) \leq F\left(d\left(x_{0}, x_{1}\right)\right)-n \tau \text { for each } n \in \mathbb{N} .
$$

Letting $n \rightarrow \infty$ in $(2.22)$ we get $\lim _{n \rightarrow \infty} F\left(d\left(x_{n}, x_{n+1}\right)\right)=-\infty$. Thus, by property $\left(F_{2}\right)$, we have $\lim _{n \rightarrow \infty} d\left(x_{n}, x_{n+1}\right)=0$. Let $d_{n}=d\left(x_{n}, x_{n+1}\right)$ for each $n \in \mathbb{N}$. From $\left(F_{3}\right)$ there exists $k \in(0,1)$ such that

$$
\lim _{n \rightarrow \infty} d_{n}^{k} F\left(d_{n}\right)=0 \text {. }
$$

From (2.22) we have

$$
d_{n}^{k} F\left(d_{n}\right)-d_{n}^{k} F\left(d_{0}\right) \leq-d_{n}^{k} n \tau \leq 0 \text { for each } n \in \mathbb{N} .
$$

Letting $n \rightarrow \infty$ in (2.23) we get

$$
\lim _{n \rightarrow \infty} n d_{n}^{k}=0 .
$$

This implies that there exists $n_{1} \in \mathbb{N}$ such that $n d_{n}^{k} \leq 1$ for each $n \geq n_{1}$. Thus we have

$$
d_{n} \leq \frac{1}{n^{1 / k}}, \text { for each } n \geq n_{1} .
$$

To prove that $\left\{x_{n}\right\}$ is a Cauchy sequence. Consider $m, n \in \mathbb{N}$ with $m>n>$ $n_{1}$. By using the triangular inequality and (2.25) we have

$$
\begin{aligned}
d\left(x_{n}, x_{m}\right) & \leq d\left(x_{n}, x_{n+1}\right)+d\left(x_{n+1}, x_{n+2}\right)+\cdots+d\left(x_{m-1}, x_{m}\right) \\
& =\sum_{i=n}^{m-1} d_{i} \leq \sum_{i=n}^{\infty} d_{i} \leq \sum_{i=n}^{\infty} \frac{1}{i^{1 / k}} .
\end{aligned}
$$

Since $\sum_{i=1}^{\infty} \frac{1}{i^{1 / k}}$ is convergent series. Thus $\lim _{n \rightarrow \infty} d\left(x_{n}, x_{m}\right)=0$. Which implies that $\left\{x_{n}\right\}$ is a Cauchy sequence. As $(X, d)$ is complete so there exists 
$x^{*} \in X$ such that $x_{n} \rightarrow x^{*}$ as $n \rightarrow \infty$. By condition (iii) we have $\alpha\left(x_{n}, x^{*}\right) \geq$ 1 for each $n \in \mathbb{N}$. We claim that $d\left(x^{*}, T_{i} x^{*}\right)=0 \forall i \in \mathbb{N}$. On contrary suppose that $d\left(x^{*}, T_{i_{0}} x^{*}\right)>0$ for some $i_{0} \in \mathbb{N}$, there exists $n_{0} \in \mathbb{N}$ such that $d\left(x_{n}, T_{i_{0}} x^{*}\right)>0$ for each $n \geq n_{0}$. For each $n \geq n_{0}$ and for above $i_{0}$, we have

$$
\begin{aligned}
d\left(x^{*}, T_{i_{0}} x^{*}\right) \leq & d\left(x^{*}, x_{n+1}\right)+d\left(x_{n+1}, T_{i_{0}} x^{*}\right) \\
< & d\left(x^{*}, x_{n+1}\right)+\alpha\left(x_{n}, x^{*}\right) \delta\left(T_{n+1} x_{n}, T_{i_{0}} x^{*}\right) \\
< & d\left(x^{*}, x_{n+1}\right)+a_{1} d\left(x_{n}, x^{*}\right)+a_{2} d\left(x_{n}, x_{n+1}\right) \\
& +a_{3} d\left(x^{*}, T_{i_{0}} x^{*}\right)+a_{4} d\left(x_{n}, T_{i} x^{*}\right)+L d\left(x^{*}, x_{n+1}\right) .
\end{aligned}
$$

Letting $n \rightarrow \infty$ in (2.26) we have

$$
d\left(x^{*}, T_{i_{0}} x^{*}\right) \leq\left(a_{3}+a_{4}\right) d\left(x^{*}, T_{i_{0}} x^{*}\right)<d\left(x^{*}, T_{i_{0}} x^{*}\right) .
$$

Which is a contradiction. Thus $d\left(x^{*}, T_{i} x^{*}\right)=0$ for all $i \in \mathbb{N}$.

EXAMPLE 2.10. Let $X=\{0,1,2,3, \ldots\}$ and

$$
d(x, y)=\left\{\begin{array}{l}
0 \text { if } x=y, \\
x+y \text { if } x \neq y .
\end{array}\right.
$$

Define $\left\{T_{i}: X \rightarrow B(X)\right\}_{i=1}^{\infty}$ by

$$
T_{i} x=\left\{\begin{array}{l}
\{0\} \text { if } x=0, \\
\{0,1,2,3, \ldots, x\} \text { if } x \neq 0
\end{array}\right.
$$

and $\alpha: X \times X \rightarrow[0, \infty)$ by

$$
\alpha(x, y)=\left\{\begin{array}{l}
1 \text { if } x=y=0, \\
\frac{1}{2} \text { if } x, y>1, \\
0 \text { otherwise }
\end{array}\right.
$$

Take $F(x)=x+\ln (x)$ for each $x \in(0, \infty)$. Under this $F$ condition $(2.15)$ reduces to

$$
\frac{\alpha(x, y) \delta\left(T_{i} x, T_{j} y\right)}{N(x, y)} e^{\alpha(x, y) \delta\left(T_{i} x, T_{j} y\right)-N(x, y)} \leq e^{-\tau}
$$

for each $x, y \in X$ with $\min \left\{\alpha(x, y) \delta\left(T_{i} x, T_{j} y\right), N(x, y)\right\}>0$. Assume that $a_{1}=1, a_{2}=a_{3}=a_{4}=L=0$ and $\tau=\frac{1}{2}$. Clearly

$$
\min \left\{\alpha(x, y) \delta\left(T_{i} x, T_{j} y\right), d(x, y)\right\}>0
$$

for each $x, y>1$ with $x \neq y$. From (2.15) for each $x, y>1$ with $x \neq y$, we have

$$
\frac{1}{2} e^{-\frac{1}{2}(x+y)}<e^{-\frac{1}{2}} .
$$

Thus $\left\{T_{i}\right\}_{i=1}^{\infty}$ is an $F_{\alpha}$-contraction of Hardy-Roger-type with $F(x)=x+\ln x$. For $x_{0}=1$, we have $x_{1}=0 \in T_{1} x_{0}$ such that $\alpha\left(x_{0}, x_{1}\right) \geq 1$. Moreover, it is easy to see that $\left\{T_{i}\right\}_{i=1}^{\infty}$ is $\alpha$-admissible sequence and for any sequence 
$\left\{x_{n}\right\} \subseteq X$ such that $x_{n} \rightarrow x$ as $n \rightarrow \infty$ and $\alpha\left(x_{n}, x_{n+1}\right) \geq 1$ for each $n \in \mathbb{N}$, we have $\alpha\left(x_{n}, x\right) \geq 1$ for each $n \in \mathbb{N}$. Therefore by Theorem $2.9\left\{T_{i}\right\}_{i=1}^{\infty}$ has a common fixed point in $X$.

Definition 2.11. Let $(X, d)$ be a metric space and $\alpha: X \times X \rightarrow[0, \infty)$ be a function. A sequence of mappings $\left\{T_{i}: X \rightarrow B(X)\right\}_{i=1}^{\infty}$ is an $F_{\alpha} *-$ contraction of Hardy-Rogers-type, if there exist $F \in \mathfrak{F}$ and $\tau>0$ such that for each $i, j \in \mathbb{N}$, we have

$$
\tau+F\left(\alpha_{*}\left(T_{i} x, T_{j} y\right) \delta\left(T_{i} x, T_{j} y\right)\right) \leq F(N(x, y)),
$$

for each $x, y \in X$, whenever $\min \left\{\alpha_{*}\left(T_{i} x, T_{j} y\right) \delta\left(T_{i} x, T_{j} y\right), N(x, y)\right\}>0$, where

$$
N(x, y)=a_{1} d(x, y)+a_{2} d\left(x, T_{i} x\right)+a_{3} d\left(y, T_{j} y\right)+a_{4} d\left(x, T_{j} y\right)+L d\left(y, T_{i} x\right) \text {, }
$$

with $a_{1}, a_{2}, a_{3}, a_{4}, L \geq 0$ satisfying $a_{1}+a_{2}+a_{3}+2 a_{4}=1$ and $a_{3} \neq 1$.

THEOREM 2.12. Let $(X, d)$ be a complete metric space and let $\left\{T_{i}: X \rightarrow\right.$ $B(X)\}_{i=1}^{\infty}$ be an $F_{\alpha}$ *-contraction of Hardy-Rogers-type satisfying the following conditions:

(i) $\left\{T_{i}\right\}_{i=1}^{\infty}$ is $\alpha_{*}$-admissible sequence;

(ii) there exist $x_{0} \in X$ and $x_{1} \in T_{i} x_{0}$ for some $i \in \mathbb{N}$ with $\alpha\left(x_{0}, x_{1}\right) \geq 1$;

(iii) for any sequence $\left\{x_{n}\right\} \subseteq X$ such that $x_{n} \rightarrow x$ as $n \rightarrow \infty$ and $\alpha\left(x_{n}, x_{n+1}\right) \geq 1$ for each $n \in \mathbb{N}$, we have $\alpha\left(x_{n}, x\right) \geq 1$ for each $n \in \mathbb{N}$. Then the mappings in a sequence $\left\{T_{i}\right\}_{i=1}^{n}$ have a common fixed point.

Proof. The proof of this theorem runs along the same lines as the proof of Theorem 2.9 .

\section{Application}

In this section, as a consequence of our result we establish an existence theorem for a system of integral equations. Let $X=(C[a, b], \mathbb{R})$ be the space of all real valued continuous functions defined on $[a, b]$. Note that $X$ is complete $([25])$ with respect to the metric $d_{\tau}(x, y)=\sup _{t \in[a, b]}\{\mid x(t)-$ $\left.y(t) \mid e^{-|\tau t|}\right\}$.

Consider the system of integral equations of the form

$$
x(t)=f(t)+\int_{a}^{b} K_{i}(t, s, x(s)) d s,
$$

for $t, s \in[a, b]$ and $i \in\{1,2,3, \cdots, N\}$ with $N \in \mathbb{N}$. Where $K_{i}:[a, b] \times[a, b] \times$ $\mathbb{R} \rightarrow \mathbb{R}$ and $f:[a, b] \rightarrow \mathbb{R}$ are continuous functions.

Theorem 3.1. Let $X=(C[a, b], \mathbb{R})$ and let $\left\{T_{i}: X \rightarrow X\right\}_{i=1}^{N}$ be the operators defined as

$$
T_{i} x(t)=f(t)+\int_{a}^{b} K_{i}(t, s, x(s)) d s,
$$


for $t, s \in[a, b]$. Where $K_{i}:[a, b] \times[a, b] \times \mathbb{R} \rightarrow \mathbb{R}$ and $f:[a, b] \rightarrow \mathbb{R}$ are continuous functions. Assume that there exist $\gamma: X \rightarrow(0, \infty), \alpha: X \times X \rightarrow$ $(0, \infty)$ and the following conditions hold:

(i) for each $i, j \in\{1,2,3, \cdots, N\}$ there exists $\tau>0$ such that

$$
\left|K_{i}(t, s, x)-K_{j}(t, s, y)\right| \leq \frac{e^{-\tau}}{\gamma(x+y)}|x-y|
$$

for each $t, s \in[a, b]$ and $x, y \in X$. Moreover,

$$
\left|\int_{a}^{b} \frac{e^{|\tau s|}}{\gamma(x+y)} d s\right| \leq \frac{e^{|\tau t|}}{\alpha(x, y)}
$$

for each $t \in[a, b]$;

(ii) for $x, y \in X, \alpha(x, y) \geq 1$ implies $\alpha\left(T_{i} x, T_{j} y\right) \geq 1$ for each $i, j \in$ $\{1,2,3, \cdots, N\}$;

(iii) there exist $x_{0} \in X$ such that $\alpha\left(x_{0}, T_{i} x_{0}\right) \geq 1$ for some $i \in$ $\{1,2,3, \cdots, N\}$;

(iv) for any sequence $\left\{x_{n}\right\} \subseteq X$ such that $x_{n} \rightarrow x$ as $n \rightarrow \infty$ and $\alpha\left(x_{n}, x_{n+1}\right) \geq 1$ for each $n \in \mathbb{N}$, we have $\alpha\left(x_{n}, x\right) \geq 1$ for each $n \in \mathbb{N}$.

Then the system of integral equations (3.1) has a solution in $X$.

Proof. First we show that $\left\{T_{i}\right\}$ is an $F_{\alpha}$-contraction of Hardy-Rogerstype. For each $i, j \in\{1,2,3, \cdots, N\}$, we have

$$
\begin{aligned}
\left|T_{i} x(t)-T_{j} y(t)\right| & \leq \int_{a}^{b}\left|K_{i}(t, s, x(s))-K_{j}(t, s, y(s))\right| d s \\
& \leq \int_{a}^{b} \frac{e^{-\tau}}{\gamma(x(s)+y(s))}|x(s)-y(s)| d s \\
& =\int_{a}^{b} \frac{e^{-\tau} e^{|\tau s|}}{\gamma(x(s)+y(s))}|x(s)-y(s)| e^{-|\tau s|} d s \\
& \leq e^{-\tau} d_{\tau}(x, y) \int_{a}^{b} \frac{e^{|\tau s|}}{\gamma(x(s)+y(s))} d s \leq \frac{e^{|\tau t|}}{\alpha(x, y)} e^{-\tau} d_{\tau}(x, y) .
\end{aligned}
$$

Thus we have

$$
\alpha(x, y)\left|T_{i} x(t)-T_{j} y(t)\right| e^{-|\tau t|} \leq e^{-\tau} d_{\tau}(x, y) .
$$

Equivalently,

$$
\alpha(x, y) d_{\tau}\left(T_{i} x, T_{j} y\right) \leq e^{-\tau} d_{\tau}(x, y) .
$$

Clearly natural logarithm belongs to $\mathfrak{F}$. Applying it on above inequality we get

$$
\ln \left(\alpha(x, y) d_{\tau}\left(T_{i} x, T_{j} y\right)\right) \leq \ln \left(e^{-\tau} d_{\tau}(x, y)\right),
$$

after some simplification we get

$$
\tau+\ln \left(\alpha(x, y) d_{\tau}\left(T_{i} x, T_{j} y\right)\right) \leq \ln \left(d_{\tau}(x, y)\right) .
$$


Thus $\left\{T_{i}\right\}_{i=1}^{N}$ is an $F_{\alpha}$-contraction of Hardy-Rogers-type with $a_{1}=1, a_{2}=$ $a_{3}=a_{4}=L=0$ and $F(x)=\ln x$. Therefore by 2.9 it follows that the system of operators (3.2) have a common fixed point, that is, the system of integral equations (3.1) has a solution in $X$.

\section{REFERENCES}

[1] O. Acar and I. Altun, A fixed point theorem for multivalued mappings with $\delta$-distance, Abstr. Appl. Anal. 2014, Art. ID 497092, 5 pp.

[2] M. U. Ali, T. Kamran and E. Karapinar, Further discussion on modified multivalued $\alpha_{*}-\psi-$ contractive type mapping, Filomat 29 (2015), 1893-1900.

[3] M. U. Ali, T. Kamran and E. Karapinar, A new approach to $(\alpha, \psi)$-contractive nonself multivalued mappings, J. Inequal. Appl. 2014, 2014:71, 9 pp.

[4] M. U. Ali, Q. Kiran and N. Shahzad, Fixed point theorems for multivalued mappings involving $\alpha$-function, Abstr. Appl. Anal. 2014, Art. ID 409467, 6pp.

[5] M. U. Ali, T. Kamran and N. Shahzad, Best proximity point for $\alpha$ - $\psi$-proximal contractive multimaps, Abstr. Appl. Anal. 2014, Art. ID 181598, 6pp.

[6] M. U. Ali and T. Kamran, On $\left(\alpha^{*}, \psi\right)$-contractive multi-valued mappings, Fixed Point Theory Appl. 2013, 2013:137, 7pp.

[7] J. H. Asl, S. Rezapour and N. Shahzad, On fixed points of $\alpha-\psi$-contractive multifunctions, Fixed Point Theory Appl. 2012, 2012:212, 6pp.

[8] R. Batra and S. Vashistha, Fixed points of an F-contraction on metric spaces with a graph, Int. J. Comput. Math. 91 (2014), 2483-2490.

[9] M. Berinde and V. Berinde, On a general class of multi-valued weakly Picard mappings, J. Math. Anal. Appl. 326 (2007), 772-782.

[10] F. Bojor, Fixed points of Kannan mappings in metric spaces endowed with a graph, An. Stiint. Univ. "Ovidius" Constanta Ser. Mat. 20 (2012), 31-40.

[11] Y. Feng and S. Liu, Fixed point theorems for multi-valued contractive mappings and multi-valued Caristi type mappings, J. Math. Anal. Appl. 317 (2006), 103-112.

$[12]$ S. H. Cho, Fixed point theorems for $\alpha-\psi$-contractive type mappings in metric spaces, Appl. Math. Sci. (Ruse) 7 (2013), 6765-6778.

[13] M. Cosentino and P. Vetro, Fixed point results for F-contractive mappings of HardyRogers-type, Filomat 28 (2014), 715-722.

[14] H. Aydi, E. Karapinar and B. Samet, Fixed points for generalized $(\alpha, \psi)$-contractions on generalized metric spaces, J. Inequal. Appl. 2014, 2014:229, 16pp.

[15] E. Karapinar, Discussion on $(\alpha, \psi)$ contractions on generalized metric spaces, Abstr. Appl. Anal. 2014, Art. ID 962784, 7pp.

[16] E. Karapinar and B. Samet, Generalized $\alpha$ - $\psi$-contractive type mappings and related fixed point theorems with applications, Abstr. Appl. Anal. 2012, Art. ID 793486.

[17] E. Karapinar and R. P. Agarwal, A note on 'Coupled fixed point theorems for $\alpha$ $\psi$-contractive-type mappings in partially ordered metric spaces', Fixed Point Theory Appl. 2013, 2013:216, 16pp.

[18] M. A. Miandaragh, M. Postolache and Sh. Rezapour, Some approximate fixed point results for generalized $\alpha$-contractive mappings, Politehn. Univ. Bucharest Sci. Bull. Ser. A Appl. Math. Phys. 75 (2013), 3-10.

[19] G. Minak and I. Altun, Some new generalizations of Mizoguchi-Takahashi type fixed point theorem, J. Inequal. Appl. 2013, 2013:493, 10pp.

[20] G. Minak, A. Helvaci and I. Altun, Ćirić type generalized F-contractions on complete metric spaces and fixed point results, Filomat 28 (2014), 1143-1151.

[21] B. Mohammadi, S. Rezapour and N Shahzad, Some results on fixed points of $\alpha-\psi$ Ciric generalized multifunctions, Fixed Point Theory Appl. 2013, 2013:24, 10pp. 
[22] D. Paesano and C. Vetro, Multi-valued F-contractions in O-complete partial metric spaces with application to Volterra type integral equation, Rev. R. Acad. Cienc. Exactas Fs. Nat. Ser. A Math. RACSAM 108 (2014), 1005-1020.

[23] H. K. Pathak and N. Shahzad, Fixed point results for set-valued contractions by altering distances in complete metric spaces, Nonlinear Anal. 70 (2009), 2634-2641.

[24] H. Piri and P. Kumam, Some fixed point theorems concerning F-contraction in complete metric spaces, Fixed Point Theory Appl. 2014, 2014:210, 11pp.

[25] D. O'Regan and A. Petrusel, Fixed point theorems for generalized contractions in ordered metric spaces, J. Math. Anal. Appl. 341 (2008), 1241-1252.

[26] B. Samet, C. Vetro and P. Vetro, Fixed point theorems for $\alpha$ - $\psi$-contractive type mappings, Nonlinear Anal. 75 (2012), 2154-2165.

[27] P. Salimi, A. Latif and N. Hussain, Modified $\alpha-\psi$-contractive mappings with applications, Fixed Point Theory Appl. 2013, 2013:151, 19pp.

[28] N.-A. Secelean, Iterated function systems consisting of F-contractions, Fixed Point Theory Appl. 2013, 2013:277, 13pp.

[29] M. Sgroi and C. Vetro, Multi-valued F-contractions and the solution of certain functional and integral equations, Filomat 27 (2013), 1259-1268.

[30] W. Shatanawi and M. Postolache, Some fixed point results for a G-weak contraction in G-metric spaces, Abstr. Appl. Anal. 2012, Art. ID 815870, 19 pp.

[31] T. Sistani and M. Kazemipour, Fixed point theorems for $\alpha$ - $\psi$-contractions on metric spaces with a graph, J. Adv. Math. Stud. 7 (2014), 65-79.

[32] S. L. Singh, S. N. Mishra and S. Jain, Round-off stability for multi-valued maps, Fixed Point Theory Appl. 2012, 2012:12, 10pp.

[33] D. Wardowski, Fixed points of a new type of contractive mappings in complete metric spaces, Fixed Point Theory Appl. 2012, 2012:94, 6pp.

T. Kamran

Department of Mathematics

Quaid-i-Azam University

Islamabad

Pakistan

and

Department of Mathematics, School of Natural Sciences

National University of Sciences and Technology

Islamabad

Pakistan

E-mail: tayyabkamran@gmail.com

Fahimuddin

Department of Mathematics

Quaid-i-Azam University

Islamabad

Pakistan

E-mail: fahamiiu@gmail.com

M. U. Ali

Department of Mathematics

COMSATS Institute of Information Technology

Attock

Pakistan

E-mail: muh_usman_ali@yahoo.com

Received: 24.11.2015.

Revised: 29.6.2016. 